\title{
ОСОБЕННОСТИ ПРИМЕНЕНИЯ РЕНТГЕНОЭНДОВАСКУЛЯРНЫХ МЕТОДОВ ГЕМОСТАЗА И ОЦЕНКА ЕГО ЭФФЕКТИВНОСТИ У БОЛЬНЫХ ПРИ ЛЕГОЧНОМ КРОВОТЕЧЕНИИ РАЗЛИЧНОЙ ЭТИОЛОГИИ
}

\section{В. В. Бойко, Е. В. Пономарева, А. Г. Краснояружский, Д. В. Минухин, Ю. В. Авдосьев \\ Институт общей и неотложной хирургии имени В. Т. Зайцева НАМН Украины, г. Харьков \\ PECULIARITIES OF APPLICATION OF ROENTGENENDOVASCULAR METHODS OF HEMOSTASIS AND ESTIMATION OF ITS EFFICACY IN PATIENTS, SUFFERING PULMONARY HEMORRHAGE OF VARIOUS ETIOLOGY}

\author{
V. V. Boyko, E. V. Ponomareva, A. G. Krasnoyaruzhskiy, D. V. Minukhin, Yu. V. Avdosyev \\ Zaitsev Institute of General and Urgent Surgery, Kharkov
}

Реферат

Представлены результаты применения рентгеноэндоваскулярного гемостаза у 117 больных при легочном кровотечении (ЛК) различной этиологии. Изучены эффективность и целесообразность использования рентгеноэндоваскулярных методов в лечении больных по поводу ЛК. Доказано, что рентгеноэндоваскулярная окклюзия (РЭО) - миниинвазивный высокоэффективный метод остановки всех типов кровотечения в бассейне бронхиальных артерий, который можно применить у пациентов даже в крайне тяжелом состоянии.

Ключевые слова: бронхиальные артерии; легочное кровотечение; рентгеноэндоваскулярный гемостаз.

Abstract

Results of application of roentgenendovascular hemostasis in 117 patients, suffering pulmonary hemorrhage (PH)of various etiology, are presented. Efficacy and expediency of application of roengenendovascular methods and treatment of patients, suffering PH, were studied. There was proved, that roentgenendovascular occlusion - miniinvasive highly-effective method of arrest of all types of hemorrhage in the basin of bronchial arteries, which may be applied even in patients with extremely severe state.

Keywords: bronchial arteries; pulmonary hemorrhage; roentgenendovascular hemostasis.

Легочное кровотечение (ЛК) и кровохарканье являются одними из наиболее грозных и частых осложнений заболеваний легких различной этиологии, свидетельствующих о глубоком повреждении бронхо-легочных структур, существенно отягощающих состояние больного $[1,2]$. Источником кровотечения может быть любой сосуд легкого. Однако большинство авторов считаЮт, что основным источником кровотечения являются сосуды артериальной части большого круга кровообращения: бронхиальные артерии и их разветвления, межреберные артерии, артерии плевры. Это тяжелое осложнение выявляют при различных заболеваниях легких у 7 - 14\% пациентов, которых госпитализируют в торакальное отделение, при этом кровотечение III степени возникает у 5 - 7\% пациентов [3, 4]. Несмотря на значительный прогресс в этой отрасли хирургии, связанный с внедрением миниинвазивных методов лечения, сложность оказания помощи пациентам при ЛК в том, что в неотложной ситуации хирург ограничен во времени, необходимом для установления источника кровотечения $[5,6]$. Это особенно актуально у больных при профузном кровотечении. Тип кровотечения (бронхиальное, альвеолярное, смешанное) определяют по данным бронхоскопии, компьютерной ангиографии. В большинстве лечебных учреждений основными методами диагностики ЛК являются рентгенологический и эндоскопический $[7,8]$. Однако даже использование обзорной рентгенографии и бронхографии не всегда позволяет установить причину кровотечения и его локализацию. В 1974 г. впервые выполнена удачная эмболизация бронхиальных артерий у пациента при массивном ЛК. Первыми выполнили экстренную эмболизацию бронхиаль- ных артерий на высоте кровотечения в 1977 г. И. Х. Рабкин, Л. Н. Готман [7]. Введение в клиническую практику с 1988 г. микрокатетерных технологий расширило возможности метода [9]. В настоящее время эмболизацию бронхиальных артерий широко применяют во всем мире [4 - 6].

Ангиографические признаки ЛК подробно изучены [7]. Выделяют прямые и косвенные признаки ЛК. К прямым признакам относят экстравазацию рентгеноконтрастного вещества, а также симптом культи бронхиальной артерии, обусловленный организованным тромбом [10]. Экстравазацию рентгеноконтрастного вещества выявляют на бронхиальных ангиограммах у 5 - 7\% пациентов [9, 10]. К косвенным признакам кровотечения относят диффузную или ограниченную гиперваскуляризацию, расширение бронхиальных артерий более 3 мм, расширение межартериальных шунтов. У боль- 
шинства пациентов РЭО бронхиальных артерий осуществляют при выявлении комплекса косвенных признаков кровотечения. Наибольшие трудности возникают у пациентов при диффузном двустороннем поражении легких. В такой ситуации ангиографическая диагностика источника кровотечения должна основываться только на прямых признаках. Выбор эмболизирующего материала зависит от его доступности. В литературе приведены единичные наблюдения, в которых в качестве эмболизирующего материала использовали гемостатическую губку [5, 6], большинство же авторов используют нерассасывающиеся материалы для достижения постоянной окклюзии артерий. Тем не менее, поиск новых эмболизирующих материалов продолжается. В литературе есть сообщения о применении для эмболизации бронхиальных артерий частиц нового материала триакрила $[2,10]$. Для эмболизации используют также спирали и отделяющиеся баллоны. Однако при применении этих устройств возможна проксимальная окклюзия с быстрым развитием коллатерального кровотока и возникновением рецидива кровотечения. Некоторые исследователи отдают предпочтение микроспиралям. По их мнению, основным достоинством микроспиралей является отсутствие осложнений, связанных с рефлюксом частиц в магистральный кровоток [6,9]. Применяют жидкие агенты: этанол, медицинский клей. Однако большинство авторов предупреждают, что эти эмболизаты следует использовать с осторожностью из-за возможных осложнений. Совершенствование рентгеноконтрастных препаратов позволило снизить в последние годы частоту таких серьезных осложнений РЭО бронхиальных артерий, как поперечный миелит, некроз стенки аорты или бронха, обусловленные токсическим действием ионных рентгеноконтрастных веществ. Тем не менее, риск возникновения осложнений РЭО сохраняется и связан с особенностями анатомии бронхиальных артерий, которые могут участвовать в кровоснабжении не только бронхов, но и других органов
[6]. Наиболее тяжелым осложнением РЭО бронхиальных артерий является нарушение кровообращения в бассейне передней спинномозговой артерии с тяжелыми неврологическими расстройствами, возникновением параплегии, нарушением функции органов таза. У 5\% пациентов спинномозговая артерия начинается от бронхиальной артерии. Наиболее часто РЭО бронхиальных артерий выполняли у пациентов при диффузном двустороннем поражении легких. При этом не решен вопрос об объеме вмешательства, болышинство авторов считают необходимой эмболизацию всех патологически-измененных бронхиальных артерий и системных коллатералей $[7,10]$.

Основным недостатком метода является высокая частота рецидивов ЛК. Так, у 15 - 20\% пациентов рецидивы кровотечения возникают в первые 6 мес после вмешательства, у 25 - 30\% - в более отдаленном периоде [10]. Сообщения об отдаленных результатах РЭО бронхиальных артерий единичны.

Причинами ЛК, по поводу которых выполняют РЭО бронхиальных артерий, наиболее часто являются бронхоэктатическая болезнь, хронический обструктивный бронхит, хронический абсцесс. Исследования зарубежных авторов посвящены неспецифическим заболеваниям легких $[5,6]$, исследования злокачественного поражения легких, острых воспалительных процессов немногочисленны $[4,8]$. Частота успешной эмболизации составляет 60 - 100\%, полное прекращение кровохарканья отмечено в 44\% наблюдений [8].

Цель исследования: изучение особенностей применения и оценка эффективности рентгеноэндоваску-

\section{Таблица 1. Причины возникновения лк}

\begin{tabular}{|lcc|}
\hline \multicolumn{1}{|c|}{ Причина } & \multicolumn{2}{c|}{ Число пациентов } \\
\cline { 2 - 3 } & абс. & $\%$ \\
\hline Хроническое обструктивное заболевание легких & 48 & 41,3 \\
\hline Бронхоэктатическая болезнь & 25 & 21,3 \\
\hline Абсцесс легких & 16 & 13,6 \\
\hline Внегоспитальная пневмония & 12 & 10,2 \\
\hline Рак легкого центральной локализации & 16 & 13,6 \\
\hline Всего ... & 117 & 100 \\
\hline
\end{tabular}

лярных методов лечения больных по поводу ЛК.

\section{МАТЕРИАЛЫ И МЕТОДЫ ИССЛЕДОВАНИЯ}

За период 2011 - 2016 гг. в клинике по поводу ЛК обследовали и лечили 117 больных в возрасте от 22 до 76 лет, мужчин - 85 (72,7\%), женщин - 32 (27,3\%).

Показаниями к проведению катетерной эмболизации бронхиальных артерий были: неэффективность консервативной терапии ЛК; кровохарканье у больных при двустороннем воспалительном процессе, которым не показано хирургическое лечение по ряду причин; отсутствие грубых морфологических изменений, требующих резекции легкого; массивное опасное для жизни профузное кровотечение в качестве средства временной или постоянной его остановки, в основном у больных при опухолевом поражении легких (табл. 1). Лечение применяли либо во время кровотечения или не позже чем через 6 - 12 ч после его остановки.

Рентгеноэндоваскулярную эмболизацию бронхиальных артерий выполняли с использованием ангиографического комплекса на аппарамы Siemens (Германия ) и «IntegrisAllura12 C» фирмы «Phillips» (Голландия). Под местной анестезией (0,25\% раствор новокаина) катетеризировали бедренную артерию по Сельдингеру с использованием катетеpa с изгибом $45-65^{\circ}$ типа Cobra. Под контролем монитора вводили катетер до уровня $\mathrm{T}_{\mathrm{IV}}-\mathrm{T}_{\mathrm{V}}$ позвонка, затем вращательными движениями зонда катетер устанавливали в устье бронхиальной или межреберной артерии. Для контроля положения катетера в нужном сосуде вводите «Tridoros-Optimatic-1000» фир- 


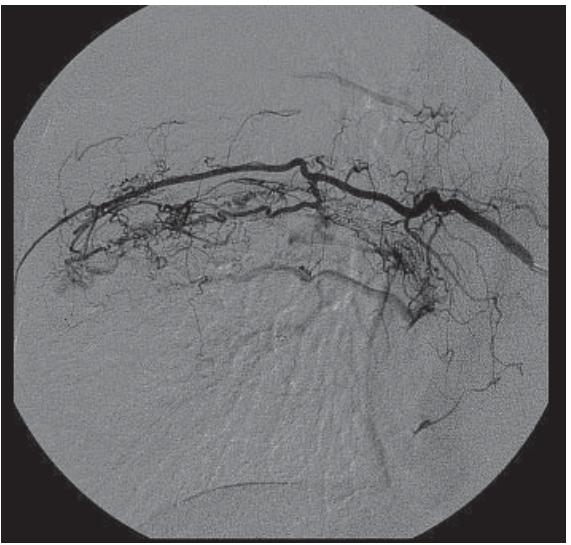

Рис. 1.

Ангиография. ЛК бронхиального типа.

ли 1 мл контрастного вещества (омнипак). Для эмболизации использовали полиуретановые эмболы диаметром 450 - 720 мкм, при большем диаметре патологически-измененного сосуда вводили эмболы в сочетании с микроспиралями, что повышало эффект эмболизации. Критерием эффективности РЭО было отсутствие поступления контрастного вещества и контрастирования дистальных отделов бронхиальных артерий. Контрольное контрастирование также позволяло исключить дополнительное кровоснабжение патологически-измененной зоны легкого аномальными сосудами.

\section{РЕЗУЛЬТАТЫ \\ И ИХ ОБСУЖДЕНИЕ}

По данным проведенной в неотложном порядке ангиографии, у всех пациентов выявлено кровотечение из басейна бронхиальных ар-

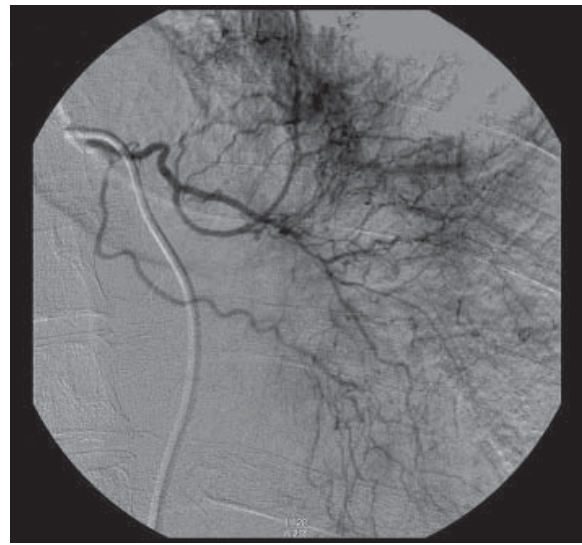

Рис. 2.

Ангиография. ЛК альвеолярного типа.

терий, в том числе у 12 пациентов альвеолярное, у 83 - бронхиальное, у 22 - смешанное. При ЛК бронхиального типа на ангиограммах четко видно поступление контрастного вещества в трахеобронхиальное дерево (рис. 1).

При кровотечении альвеолярного типа контрастное вещество задерживалось в виде пятен в паренхиматозную и венозную фазы (рис. 2).

При ЛК альвеолярного и смешанного типа сложнее определить источник кровотечения и, соответственно, объем планируемой РЭО. Необходимо выполнить ангиопульмонографию, чтобы исключить кровотечение из бассейна легочной артерии, и бронхоскопию, чтобы провести эмболизацию бронхиальных артерий на стороне поражения.

Структура выполненных рентгеноэндоваскулярных операций представлена в табл. 2.
После РЭО пациентам проводили видеоэндоскопический контроль достижения гемостаза. Рецидив кровотечения после РЭО возник у 5 (4,3\%) пациентов при неоперабельном раке легкого центральной локализации. Ишемических осложнений, связанных с РЭО бронхиальных артерий, в ближайшем послеоперационном периоде не наблюдали. После операции умерли 3 (2,6\%) больных, до операции их состояние было крайне тяжелым вследствие полиорганной недостаточности на фоне осложнений основного заболевания.

\section{выводы}

1. Артериография бронхиальных артерий в сочетании с видеобронхоскопией является «золотым стандартом» диагностики ЛК, позволяет установить точный диагноз благодаря выявлению специфических ангиографических и бронхоскопических признаков.

2. Показаниями к РЭО бронхиальных артерий были: неэффективность консервативной терапии; кровохарканье у больных при двустороннем воспалительном процессе; массивное и профузное кровотечение, в качестве средства его временной или постоянной остановки.

3. РЭО является миниинвазивным высокоэффективным методом остановки всех типов кровотечения из бассейна бронхиальных артерий, ее можно применять даже у пациентов в состоянии крайней степени тяжести.

Таблица 2. Структура выполненных РЭО

\begin{tabular}{|c|c|c|c|c|c|}
\hline \multirow[b]{2}{*}{ Тип ЛК } & \multicolumn{3}{|c|}{ Вид РЭО } & \multicolumn{2}{|c|}{ Число больных } \\
\hline & микроэмболы & микроспирали & $\begin{array}{c}\text { микроэмболы, } \\
\text { спирали }\end{array}$ & абс. & $\%$ \\
\hline \multicolumn{6}{|l|}{ Бронхиальное } \\
\hline одностороннее & 36 & 14 & 21 & 71 & 60,6 \\
\hline двустороннее & 9 & - & 3 & 12 & 10,2 \\
\hline \multicolumn{6}{|l|}{ Альвеолярное } \\
\hline одностороннее & 3 & - & 1 & 4 & 3,4 \\
\hline двустороннее & 5 & - & 3 & 8 & 6,8 \\
\hline \multicolumn{6}{|l|}{ Смешанное } \\
\hline одностороннее & 7 & 2 & 6 & 15 & 13,0 \\
\hline двустороннее & 4 & 1 & 2 & 7 & 6,0 \\
\hline Всего ... & 64 & 17 & 36 & 117 & 100 \\
\hline
\end{tabular}




\section{REFERENCES}

1. Borisova IA, Komissarov IA, Golbits SV, i dr. Embolizatsiya bronkhialnykh arteriy pri ostrom legochnom krovotechenii u detey. Vestnik khirurgii. 2015;(2):63-70. [In Russian].

2. Boyko VV, Avdos'ev YuV, Tokarev AV. Bronkhialnaya angiografiya i lechebnaya embolizatsiya bronkhialnykh arteriy u bolnykh s legochnymi krovotecheniyami. Vrachebnaya praktika. 2006;(2):63-5. [In Russian].

3. Alekseev VG, Moroz VV. Algoritmy diagnostiki i lecheniya legochnykh krovotecheniy. Obshchaya reanimatologiya. 2013;9(2):45-54. [In Russian].

4. Granov AM, Davydov MI. Interventsionnaya radiologiya v onkologi. SPb.: Foliant; 2013. 543 s. [In Russian].

5. Trukhan D. I. Krovokharkanie: differentsialno-diagnosticheskie aspekty na etape okazaniya pervichnoy mediko-sanitarnoy pomoshchi. Spravochnik poliklinicheskogo vracha. 2015;(6-8):56-60. [In Russian].
6. Shipulin PP, Severgin VE, Kuznetsov NA, i dr. Opyt primeneniya rentgenendovaskulyarnoy embolizatsii bronkhial'ykh arteriy $v$ lecheni legochnogo krovotecheniya. Klinichna Khirurhiia. 2013;(10):38-40. [In Russian].

7. Perelman MI. Legochnoe krovotechenie. Consilium Medicum 2006:88-92. [In Russian].

8. Alexander GR. A retrospective review comparing the treatment outcomes of emergency lung resection for massive haemoptysis with and without preoperative bronchial artery embolization. Eur J Cardiothorac Surg. 2014;45(2):251-5.

9. Gunnarsson O, Bjoernsson E, Reynisson K, et al. Bronchial artery embolization as a treatment for massive hemoptysis. A case report. Laeknabladid. 2006;92(3):197-9.

10. Sopko DR, Smith TP. Bronchial Artery Embolization for Hemoptysis. Seminars in Interventional Radiology. 2011;28(1):48-51. 